\title{
Efficacy of a Salmonella live vaccine for turkeys in different age groups and antibody response of vaccinated and non-vaccinated turkeys
}

\author{
Martina Hesse* ${ }^{*}$, Andreas Stamm, Rita Weber and Gerhard Glünder
}

\begin{abstract}
Objective: Human Salmonellosis continues to be one of the most important foodborne zoonoses worldwide, although a decrease in case numbers has been noted in recent years. It is a foodborne zoonotic infection most commonly associated with the consumption of raw egg products but also with meat consumption including the consumption of poultry products. Turkey flocks in Europe have been reported to be affected by Salmonella infection, too. The present study examines the efficacy of a newly licensed Salmonella life vaccine in reducing infections with the Salmonella serovars Typhimurium and Enteritidis in turkeys. Turkeys were vaccinated the first day of life and at the age of 6 and 16 weeks. Groups of birds which had received different numbers of vaccinations were then submitted to challenge trials with either SE or ST.
\end{abstract}

Results: In vaccinated birds Salmonella counts in liver and spleen and, less effectively, in caecum were reduced compared to unvaccinated birds. In several groups serum antibody-titers were statistically significantly higher in vaccinated turkeys than in non-vaccinated ones at day seven post infection, but only in one out of six groups at day 14 post infection.

Keywords: Salmonella, Turkey, Immunization, Antibody response

\section{Introduction}

Non-host-adapted Salmonellae usually colonize the digestive tract of turkeys asymptomatically $[1,2]$. Although in case of stress or at a very young age turkeys may develop severe clinical signs [1], the most important problem resulting from Salmonella infections lies in the transmission to humans. The main source of food-borne Salmonella outbreaks is the consumption of table eggs and egg products, but single samples of fresh turkey meat yielded the highest proportion of Salmonella-positive results $[3,4]$. Control strategies focus on hygiene and management but also include vaccination $[5,6]$. Despite a recent decrease of the prevalence of human Salmonellosis

\footnotetext{
*Correspondence: martina.hesse@tiho-hannover.de; martinahesse@hotmail.com

Clinic for Poultry, University of Veterinary Medicine Hannover, Bünteweg 17, Hannover, Germany
}

in several European countries it is still one of the most important food borne zoonoses in Europe [7, 8]. Vaccination of turkeys might help to reduce prevalence in turkey flocks and transmission to humans further. Barrow et al. [9] stress that the use of vaccines has been empirical and that immunological studies about Salmonella infections in turkeys are still scarce, although certain aspects of the humoral immune response have been studied before [10-12]. In two recent studies we examined a bivalent live Salmonella vaccine for its ability to induce primary immune reactions after vaccination of 1 day old turkeys [13] and for its protective efficacy in turkey poults against Salmonella challenge infections at the age of 3 weeks [14].The latter study found lower Samonella counts in liver, spleen and caecum of vaccinated turkey poults compared to unvaccinated poults in challenge trials at 3 weeks of age. No domination of either a $\mathrm{T}_{\mathrm{H}} 1$-response 
or a $\mathrm{T}_{\mathrm{H}} 2$-response could be determined and no statistically significant difference regarding the IgG serum antibody response between vaccinated and non-vaccinated turkeys after challenge infection was found.

The aim of the present study was to examine the protective effect of the mentioned vaccine against Salmonella Enteritidis (SE) and Salmonella Typhimurium (ST) infections in turkeys in additional age groups and after a different number of vaccinations. The efficacy was determined by comparing bacterial counts in caeca, liver and spleen after challenge. Since it has been shown that turkeys do not produce antibodies from hatch it should also be determined if birds which were older than the birds in our former studies or which were vaccinated more often would produce a notable serum antibody-response.

\section{Main text}

\section{Materials and methods}

\section{Experimental design}

At day of hatch 320 turkeys were housed separately and divided randomly into two groups of 160 birds each. One group served as non-vaccinated control group whereas the other group was directly vaccinated with the Salmonella live vaccine. Booster immunizations were applied at the age of 6 and 16 weeks (Table 1). At 2, 6, 16 and 23 weeks of age challenge experiments were conducted (Table 1). For each challenge experiment 20 vaccinated and 20 non-vaccinated birds were infected with the virulent SE strain and 20 vaccinated and 20 non-vaccinated birds were infected with the virulent ST strain.

At day 7 and 14 post infection 10 individuals per group were sacrificed by exsanguination after they had been stupefied by manually applied blunt force trauma and samples were collected. For vaccinated birds which were infected with SE at 6 weeks of age only serum samples of four birds at 7 and 14 days post infection could be examined.

\section{Experimental animals}

At the day of hatch commercially available female fattening turkeys type BUT Big 6 (MoorgutKartzfehn von Kameke GmbH\&Co.KG, Germany) were housed. Continuous bacteriological and serological monitoring of the parent flock and of the poults upon arrival were conducted to ascertain that the birds were free of Salmonella at that stage of the study. The different groups were kept separately in isolation units accordant to their immunization or infection status. Cross contamination between the immunized group and the control group and between the four groups in the challenge experiments was effectively prevented by separate air conditioning, a separate feeding regime and the change of clothing as well as strict disinfection of the facilities. Commercial starter feed and water from the municipal water supply were offered ad libitum. No antibiotics were added to feed or drinking water. Water from the municipal water supply in Germany is suitable to be used as drinking water for humans.

\section{Bacterial strains and culture}

The vaccine and the challenge strains used in this study as well as the preparation of the inocula have been previously described [13]. Birds were immunized with a commercial live vaccine ("AviPro Duo", Elanco Deutschland $\mathrm{GmbH}$, Bad Homburg). The vaccine contains the metabolic drift mutant strains Salmonella Typhimurium-strain ST Nal2/Rif9/Rtt and the Salmonella Enteritidis-strain SE Sm24/Rif12/Ssq [15]. Each vaccine dose was prepared to contain $1 \times 10^{8} \mathrm{cfu}$ of both strains per bird which was verified by decimal dilution series. For infection experiments nalidixic acid resistant mutants

Table 1 Experimental design

\begin{tabular}{|c|c|c|c|c|c|}
\hline \multirow[t]{2}{*}{ Age at challenge ${ }^{a}$} & \multicolumn{2}{|c|}{ Vaccinations before challenge } & \multirow{2}{*}{$\begin{array}{l}\text { Necropsy } \\
\text { and examination } \\
\text { Day post infection }\end{array}$} & \multicolumn{2}{|c|}{$\begin{array}{l}\text { Group designation } \\
\text { and number examined }\end{array}$} \\
\hline & Vaccinated groups & $\begin{array}{l}\text { Non- vaccinated } \\
\text { groups }\end{array}$ & & $\begin{array}{l}\text { ST vacc./non } \\
\text { vacc. }\end{array}$ & $\begin{array}{l}\text { SE vacc./non } \\
\text { vacc. }\end{array}$ \\
\hline \multirow[t]{2}{*}{2 weeks } & $1 s t d$ & - & 7 & $10 / 10$ & $10 / 10$ \\
\hline & & & 14 & $10 / 10$ & $10 / 10$ \\
\hline \multirow[t]{2}{*}{6 weeks } & 1 st d & - & 7 & $10 / 10$ & $10 / 10$ \\
\hline & & & 14 & $10 / 10$ & $10 / 10$ \\
\hline \multirow[t]{2}{*}{16 weeks } & 1 st d, 6 w & - & 7 & $10 / 10$ & $10 / 10$ \\
\hline & & & 14 & $10 / 10$ & $10 / 10$ \\
\hline \multirow[t]{2}{*}{23 weeks } & 1 st d, 6 w, 16 w & - & 7 & $10 / 10$ & $10 / 10$ \\
\hline & & & 14 & $10 / 10$ & $10 / 10$ \\
\hline
\end{tabular}

$d$ day of life, $w$ week of life

a Challenge with ST or SE, 20 turkeys per each vaccinated or non-vaccinated group 
of the virulent strains SE K482/91 [16] and STm $27 \mathrm{Nal}^{\mathrm{r}}$ of the phage type DT104 were used. The inocula of the challenge strains contained $1 \times 10^{9} \mathrm{cfu}$ per dose and were administered with a buttoned cannula directly into the crop.

\section{Bacteriology}

Samples from caecum ingesta, liver and spleen were collected during necropsies and used for quantitative reisolation of the challenge strains as described previously [13]. The samples and added phosphate buffered saline PBS were processed into a homogenous suspension with an Ultra-Thurrax ${ }^{\circledR}$ (IKA-Werke, Staufen, Germany) with dispersing tools (Omni-Tip, Omnilab, Bremen). The caecum ingesta were subjected to a decimal dilution. Two portions of every dilution step as well as the organ suspension diluted 1:4 were dispensed on agar plates selective for the antibiotic resistant challenge strains. The identification of the SE and ST challenge strains was confirmed by the affiliation to different serogroups using $\mathrm{Sal}$ monella Test-sera (REF ORND03 and REF ORNH03 by Dade Behring, Marburg, Germany).

\section{ELISA}

Blood samples of each individual were centrifuged and the serum stored at $-72{ }^{\circ} \mathrm{C}$. For antibody detection the ELISA Group B and Group D salmonella Combined Antibody Test Kit (BioChek, Reeuwijk) was used in accordance with manufacturer's instructions. It discriminates between antibodies directed against LPS antigens belonging to the Salmonella serogroups B and D.

The absorption of the samples was measured in a microtitre plate reader at $405 \mathrm{~nm}$ wavelength and compared to the absorption of a positive control. The sample to positive ratio was determined and the cutoff for positive values was set at 0.5 .

\section{Statistical analyis}

Statistical calculations were conducted with the computer program SigmaStat ${ }^{\circledR}$, Version 3.1 (Jandel, Erkrath). To detect statistically significant differences between vaccinated and unvaccinated animals t-tests were carried out if data were normally distributed. If not, Mann-WhitneyRank sum tests were employed. The significance level was set at $\mathrm{p}<0.05$ for all tests.

\section{Results and discussion}

The present study tested the effectiveness of a Salmonella live vaccine in turkeys in different age groups. To our knowledge this study is the first that assessed the effectiveness of live vaccination to prevent $S E$ infection in turkeys over such a long period of time and in so many different age groups. In the literature we could not find reports on the use of live vaccines to prevent ST infections in turkeys.

In challenge experiments vaccinated and non-vaccinated turkey poults were infected with either a virulent ST strain or a virulent SE strain. At day seven and 14 post infection caecum colonization as well as infection of liver and spleen were evaluated.

One reason for vaccination of domestic poultry is to reduce Salmonella prevalence in livestock, hence preventing the contamination of poultry products. A reduction of Salmonella in the intestine would be important for this purpose. Additionally, the prevention of systemic infection allegedly resulting in a diminished colonization of the reproductive tissues has been named as a goal of vaccination [17].

Although it has been argued that Salmonellae in the cecum lumen are not readily accessible for the humoral or cell-mediated immunity $[18,19]$, some studies found reduced cecal colonization or fecal shedding by the use of inactivated vaccines in turkeys [20-22]. Only in some of our challenge experiments presented here and in a previously published experiment [14] cecal colonization was reduced in vaccinated birds, too (Fig. 1).

At day seven post infection the re-isolation of ST from 22 weeks old vaccinated birds and the re-isolation of SE from 16 to 22-weeks-old vaccinated animals was significantly reduced compared with the non-vaccinated control group. In contrast, $14 \mathrm{dpi}$ generally more colony forming units of SE were found in the vaccinated than in the non-vaccinated turkeys with significant differences at the age of 6 and 16 weeks.

Thus, the tested vaccine does reduce cecum colonization but not as reliably as desired.

In contrast to findings in the intestine, the systemic spread of Salmonellae was reduced considerably through vaccination (Fig. 1). The counts of virulent ST and SE in livers of vaccinated birds were reduced compared to the counts in livers of non-vaccinated birds in all age groups 7 days after challenge infection. This could be confirmed statistically in all groups but one. With the exception of

(See figure on next page.)

Fig. 1 Re-isolation of virulent Salmonella strains from caecum, liver and spleen in different age groups. Figure bars represent the mean log 10 colony forming units/gram from 10 samples of caecum ingesta, liver or spleen, respectively. Error bars represent standard deviation. Statistically significant differences are indicated by different letters 

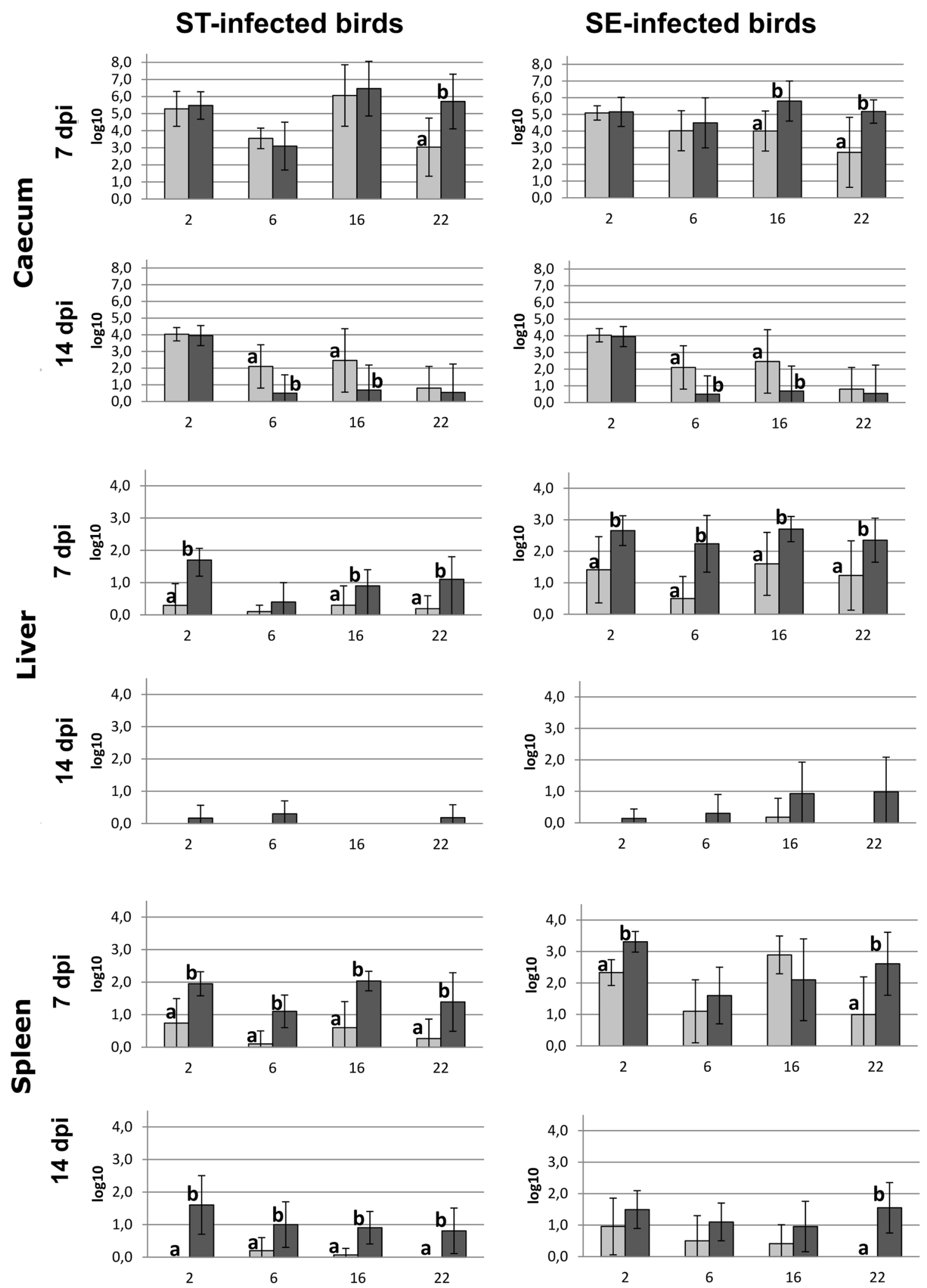

$\square$ vaccinated

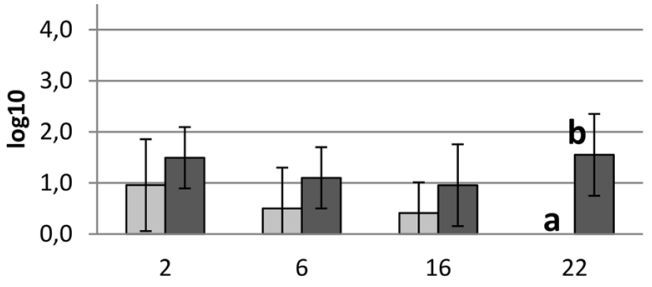

$\square$ non-vaccinated 


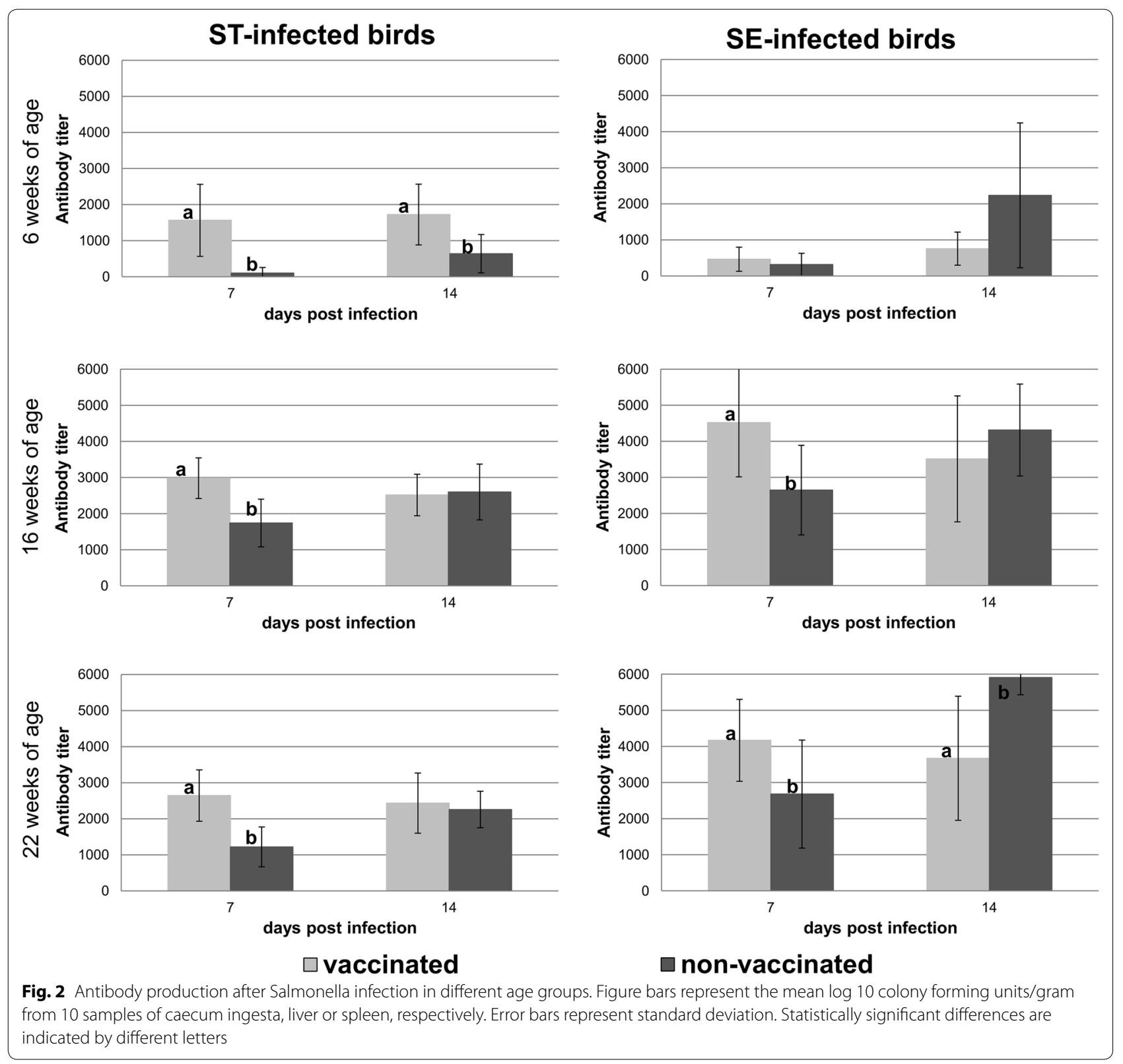

16 weeks old SE challenged birds; Salmonellae were completely eliminated from livers of vaccinated turkeys at day 14 post infection whereas the agent was still present in livers of non-vaccinated turkeys at a low level at this timepoint.

From spleens of vaccinated turkeys (Fig. 1) statistically significantly less ST were isolated than from spleens of non-vaccinated animals in all age groups at all timepoints. SE bacterial counts were statistically significantly lower at day $7 \mathrm{pi}$ in spleens of vaccinated birds which had been infected at 2 and 22 weeks of age and at day 14 pi in vaccinated birds which had been infected at 22 weeks of age.
Thus the vaccine clearly reduced systemic spread in turkeys, which is in line with previous findings by our group for 3 weeks old turkeys. In contrast Krüger et al. [23] described the failure of a live attenuated vaccine to protect turkeys against Salmonella infection in a different setting. Generally studies addressing the success of vaccination against non-host-specific Salmonella serovars in poultry have yielded differing and sometimes conflicting results [5]. For chickens (reviewed by [24]) and ducks [25] live vaccines have been reported to confer protection against Salmonella infection.

In a previous study we could not detect antibody production of either vaccinated or non-vaccinated turkeys 
after challenge at 3 weeks of age. The finding of IgG antibodies only at a very low level in young turkeys is in accordance with findings of others [26] who showed that turkeys started to produce humoral antibodies after vaccination with an inactivated Bordetella avium vaccine not before 28 days of age independently from the time of vaccination.

In the present study higher antibody titers were found in turkeys which were 6 weeks old at challenge compared to turkeys examined in our former study, which were only 3 weeks old at challenge (Fig. 2). We also found that 16- or 22-weeks old animals produced higher titers than 6 week old turkeys.

At day seven post infection vaccinated birds presented statistically significantly higher antibody titers compared to the control group with the exception of birds infected with SE at 6 weeks of age. At day 14 post infection titers generally had not changed much in vaccinated birds. In contrast antibody titers in non-vaccinated birds had risen to roughly the same level as in vaccinated birds or even higher. At day 14 post infection we could find statistically significantly higher antibody titers in vaccinated birds compared to non-vaccinated birds in the groups infected with ST at 6 weeks of age and SE at 16 weeks of age. For vaccinated birds infected at 22 weeks of age antibody titers were statistically significantly lower than in nonvaccinated birds.

In summary vaccinated birds produced antibodies earlier than non-vaccinated birds. High titers of circulating antibodies have been associated with protection against systemic infections and could therefore explain the reduced numbers of colony forming units in livers and spleens of vaccinated birds [27, 28]. Higher counts of Salmonellae in internal organs may then have induced a stronger antibody response in nonvaccinated turkeys until day 14 post challenge. Similar results of earlier antibody production in vaccinated individuals have been reported for Salmonella vaccination before [29]. However, antibody-production does not always correlate with Salmonella resistance [30-32] and in the present study we could not find a consistent relationship between antibody titers and cecum colonization or infection of internal organs.

\section{Limitations}

For the immune response against bacteria in the gut lumen IgA antibody titers in the bile would possibly be even more interesting but were not addressed in this study.

Due to the experimental design the present study cannot determine if there is a causal relationship between antibody response and protection against Salmonella challenge infections.

\section{Abbreviations}

$\mathrm{T}_{H}$ 1-response: $T$ helper type 1 response; $\mathrm{T}_{H} 2$-response: $T$ helper type 2 response; SE: Salmonella Enteritidis; ST: Salmonella Typhimuriumdpi day(s) post infection.

\section{Authors' contributions}

$\mathrm{MH}, \mathrm{AS}, \mathrm{GG}$ and RW conceived and designed the experiments; $\mathrm{MH}$ and $\mathrm{AS}$ performed the experiments; $\mathrm{MH}, \mathrm{AS}$, and GG analyzed the data; MH and GG wrote the paper. All authors read and approved the final manuscript.

\section{Acknowledgements}

The Salmonella challenge strains were kindly supplied by Lohmann Animal Health Company, Cuxhaven, Germany. The authors would like to thank Sonja Bernhardt, Sabrina Techel and Katja Stolpe for their excellent support during the animal experiments. Furthermore, we would like to thank Hilke Bartels for excellent technical assistance and advice in the laboratory. Additionally, we would like to thank Lothar Brock for checking the manuscript regarding the correct use of the English language.

\section{Competing interests}

Andreas Stamm received a scholarship from Lohmann Animal Health for work that was not directly related to the present study. Aside from that the authors declare to have no competing interests.

\section{Availability of data and materials}

The datasets used and/or analyzed during the current study are available from the corresponding author on reasonable request.

\section{Consent for publication}

Not applicable.

\section{Ethics approval and consent to participate}

The use of animals in this study was reviewed by the animal welfare officer of the University of Veterinary Medicine Hannover, which includes the scrutiny of animal welfare, ethics and handling, and then announced to the Lower Saxony State Office for Consumer Protection and Food Safety according to $\S 8 \mathrm{a}(1,2)$ of the German Animal Health and Welfare Act. Work on this study was approved under file number 33.9-42502-05-11A153 of the competent authority.

\section{Funding}

Lohmann Animal Health Company partially funded the bacteriological examinations. The ELISA was kindly provided by the manufacturer (Biochek). Any other funding was provided by the Clinic for Poultry, Hannover.

\section{Publisher's Note}

Springer Nature remains neutral with regard to jurisdictional claims in published maps and institutional affiliations.

Received: 23 March 2018 Accepted: 20 June 2018

Published online: 03 July 2018

References

1. Hafez HM, Jodas S. Salmonella Infections in Turkeys. In: Wray C, Wray A, editors. Salmonella in domestic animals. New York: CABI Publishing; 2000.

2. Gast RK. Salmonella Infections. In: Saif YM, editor. Diseases of poultry. 1st ed. Ames: lowa State University Press; 2003. p. 567-8.

3. European Food Safety Authority. Report of the task force on zoonoses data collection on the analysis of the baseline survey on the prevalence of Salmonella in turkey flocks, Part B. EFSA J. 2008;198:1-124. 
4. Bundesinstitut für Risikobewertung. Grundlagenstudie zur Erhebung der Prävalenz von Salmonellen in Truthühnerbeständen. 2008. http://www. bfr.bund.de/cm/208/grundlagenstudie_zur_erhebung_der_praevalenz _von_salmonellen_in_truthuehnerbestaenden.pdf. Accessed 16 Feb 2018

5. Immerseel FV, Methner U, Rychlik I, Nagy B, Velge P, Martin G, et al. Vaccination and early protection against non-host-specific Salmonella serotypes in poultry: exploitation of innate immunity and microbial activity. Epidemiol Infect. 2005;133:959-78.

6. O'Brien SJ. The "decline and fall" of nontyphoidal Salmonella in the United Kingdom. Clin Infect Dis. 2013;56:705-10.

7. EFSA (European Food Safety Authority) and ECDC (European Centre for Disease Prevention and Control). The European Union summary report on trends and sources of zoonoses, zoonotic agents and food-borne outbreaks in 2014. EFSA J. 2015;13:4329.

8. Robert Koch-Institut. Infektionsepidemiologisches Jahrbuch meldepflichtiger Krankheiten für 2015. Berlin: Robert Koch-Institut; 2016.

9. Barrow PA, Jones MA, Smith AL, Wigley P. The long view: salmonella - the last forty years. Avian Pathol. 2012;41:413-20.

10. Kremer CJ, O'Meara KM, Layton SL, Hargis BM, Cole K. Evaluation of recombinant Salmonella expressing the flagellar protein fliC for persistence and enhanced antibody response in commercial turkeys. Poult Sci. 2011;90:752-8

11. Thain JA, Baxter-Jones C, Wilding GP, Cullen GA. Serological response of turkey hens to vaccination with Salmonella hadar and its effect on their subsequently challenged embryos and poults. Res Vet Sci. 1984;36:320-5

12. Tenk I, Gyorvary I, Erdei P, Szabo Z, Kostyak A, Matray D. Effect on Salmonella shedding in breeding turkey flocks of vaccine (Salenvac) against Salmonella Enteritidis. Magy. Allatorvosok Lapja. 2000;122:737-41.

13. Hesse M, Stamm A, Weber R, Glünder G, Berndt A. Immune response of turkey poults exposed at 1 day of age to either attenuated or wild Salmonella strains. Vet Immunol Immunopathol. 2016;174:1-10.

14. Hesse M, Stamm A, Berndt A, Glünder G, Weber R. Immune response to Salmonella infections in vaccinated and non-vaccinated turkeys. Res Vet Sci. 2017;115:165-73.

15. Hahn I. A contribution to consumer protection: TAD Salmonella Vac E-A new live vaccine for chickens against salmonella enteriditis. Lohmann Inf. 2000;23:29-32.

16. Ludwig HJ, Calsow P. Prevention of Salmonella infections in laying hens by vaccination. Berl Munch Tierarztl Wochenschr. 1992;105:96-8.

17. Barrow PA, Methner U. Vaccination against Salmonella infections in food animals: rationale, theoretical basis and practical application. In: Barrow PA, Methner U, editors. Salmonella in domestic animals. 2nd ed. Oxfordshire; 2013. p. 455-75.

18. Barrow PA, Wallis TS. Vaccination against Salmonella in food animals: rationale, theoretical basis and practical application. In: Wray C, Wray A, editors. Salmonella in domestic animals. New York: CABI Publishing; 2000.

19. Barrow PA. Immunological control of Salmonella in poultry. In: Blankenship LC, editor. Colonization control of human bacterial enteropathologens in poultry. San Diego: Academic Press; 1991. p. 199-217.
20. Charles SD, Nagaraja KV, Sivanandan V. A lipid-conjugated immunostimulating complex subunit vaccine against Salmonella infection in turkeys. Avian Dis. 1993:37:477-84.

21. Jodas S, Hafez HM. Field investigations on the efficacy of inactivated Salmonella enteritidis vaccine (Salenvac ${ }^{\circledR}$ ) in turkey breeder flocks. In: Hafez HM, editor. Proceedings of 4th international symposium on turkey diseases. Berlin; 2002. p. 259-70

22. Nagaraja KV, Kim CJ, Pomeroy BS. Prophylactic vaccines for the control and reduction of Salmonella in turkeys. In: Proceedings 92nd annual meet. US Animal Health Association. 1988. p. 347-8.

23. Krüger A, Redmann T, Krajewski V. Field Investigations on the efficacy of a live vaccine of Salmonella Enteritidis in Meat Turkeys. In: 7th international symposium on turkey diseases. Berlin: German Veterinary Medical Society; 2008

24. Shivaprasad HL, Methner U, Barrow PA. Salmonella infections in the domestic fowl. In: Barrow PA, Methner U, editors. Salmonella in domestic animals. 2nd ed. Oxfordshire: CABI Publishing; 2013. p. 162-92.

25. Tang T, Gao Q, Barrow P, Wang M, Cheng A, Jia R, et al. Development and evaluation of live attenuated Salmonella vaccines in newly hatched duckings. Vaccine. 2015;33:5564-71.

26. Foulman A, Glünder G. Humoral immune response following immunisation of turkey poults with an inactivated Bordetella avium vaccine. In: 3 rd International symposium on turkey diseases. Berlin; 2000.

27. Clifton-Hadley FA, Breslin M, Venables LM. A laboratory study of an inactivated bivalent iron restricted Salmonella enterica serovars Enteritidis and Typhimurium dual vaccine against Typhimuirum challenge in chickens. Vet Microbiol. 2002:89:167-79.

28. Woodward MJ, Gettinby G, Breslin MF, Corkish JD, Houghton S. Theefficacy of Salenvac, a Salmonella enterica subsp. enterica serotype Enteritidisiron-restricted bacterin vaccine, in laying chickens. Avian Pathol. 2002:31:383-92.

29. Hassan JO, Mockett AP, Catty D, Barrow PA. Infection and re-infection of chickens with Salmonella Typhimurium: bacteriology and immune responses. Avian Dis. 1991;35:809-19.

30. Beal RK, Wigley P, Powers C, Barrow PA, Smith AL. Cross-reactive cellular and humoral immune responses to Salmonella enterica serovars Typhimurium and Enteritidis are associated with protection to heterologous re-challenge. Vet Immunol Immunopathol. 2006;114:84-93.

31. Berthelot-Herault F, Mompart F, Zygmunt MS, Dubray G, Duchet-Suchaux $M$. Antibody responses in the serum and gut of chicken lines differing in cecal carriage of Salmonella enteritidis. Vet Immunol Immunopathol. 2003:96:43-52

32. Beal RK, Smith AL. Antibody response to Salmonella: its induction and role in protection against avian enteric salmonellosis. Expert Rev Anti Infect Ther. 2007;5:873-81.

\footnotetext{
Ready to submit your research? Choose BMC and benefit from:

- fast, convenient online submission

- thorough peer review by experienced researchers in your field

- rapid publication on acceptance

- support for research data, including large and complex data types

- gold Open Access which fosters wider collaboration and increased citations

- maximum visibility for your research: over 100M website views per year
}

At BMC, research is always in progress.

Learn more biomedcentral.com/submissions 